\title{
Centro de cirugía mayor ambulatoria: una necesidad clínica impostergable
}

\author{
Patricia Cisternas' ${ }^{1}$ Ezio Parodi', Katalina mora', Dagoberto Ojeda
}

\begin{abstract}
Introducción: Existe consenso en considerar que cuando la cirugía se realiza en forma ambulatoria se genera un beneficio significativo para los pacientes. Se ha podido demostrar que la cirugía ambulatoria ha contribuido al control de los costos involucrados, ha disminuido el tiempo de separación de las familias y el de espera para las cirugías. Se reconoce que también ha reducido la incidencia de infecciones relacionadas con la cirugía. Ha significado mejoras en la disponibilidad de camas hospitalarias, en la utilización de los pabellones quirúrgicos y de las unidades de recuperación. Es posible que contribuya a reducir las complicaciones postoperatorias, los exámenes de laboratorio innecesarios y la demanda de analgésicos. En enero de 2017 se inauguró en nuestra clínica el Centro de Cirugía Mayor Ambulatoria. (CCMA).
\end{abstract}

Objetivos: El objetivo del presente trabajo es presentar los resultados del funcionamiento del CCMA.

Material y Método: El CCMA comprende 15 camas ambulatorias y comparte quirófanos con el pabellón central. Su horario de funcionamiento es de 07-22 horas. Los pacientes ASA I y II enrolados deben acudir el día previo a la cirugía a entrevista con la enfermera. Los pacientes ASA III requieren evaluación por el anestesiólogo. Se considera posible realizar toda cirugía que no signifique un riesgo mayor de sangramiento bajo el régimen ambulatorio. El alta del CCMA se otorga con criterio fast-tracking post cirugía ambulatoria y es responsabilidad del anestesiólogo. Se realizan 3 controles telefónicos posteriores al alta a las 12,24 y 36 horas.

Resultados: Entre enero y diciembre de 2017
3.601 pacientes fueron operados en el CCMA y 3.199 en el período de enero a agosto en 2018 llegando a representar hasta un $30 \%$ de la actividad quirúrgica mensual. Las cirugías ambulatorias más frecuentes fueron Otorrinolaringología 21\%, Oftalmología 17\%, Cirugía laparoscópica $16 \%$ y Ortopedia, incluido HNP lumbar $15 \%$. Hubo un $3,6 \%$ de hospitalización no programada, pero solo el $0,6 \%$ se debió a causas médicas como náuseas, dolor y hemorragia. Hubo un $0,5 \%$ de reingresos hospitalarios. De ellos la mayoría correspondió a sangramiento de cirugía de amígdalas pasadas las 48 horas postoperatorias. Solo hubo un reingreso de cirugía biliar laparoscópica por dolor 72 horas después del alta. No se presentaron complicaciones durante las cirugías.

Conclusiones: El CCMA ha absorbido un porcentaje importante de nuestra actividad quirúrgica, aunque aún insuficiente de acuerdo a la recomendación internacional. La incidencia de hospitalización no programada se encuentra dentro de los márgenes que muestra la literatura médica disponible. Los reingresos postoperatorios son muy infrecuentes y responden a circunstancias no controlables por la hospitalización tradicional.

\section{Referencias}

1. White PF, Update on ambulatory anesthesia. Can J Anesth 2005/52:6/R1-R10.

2. Qadir N, Smith I, Day surgery: how far can we go and are there still any limits? Curr Opin Anesthesiol 2007/20:503-507. 